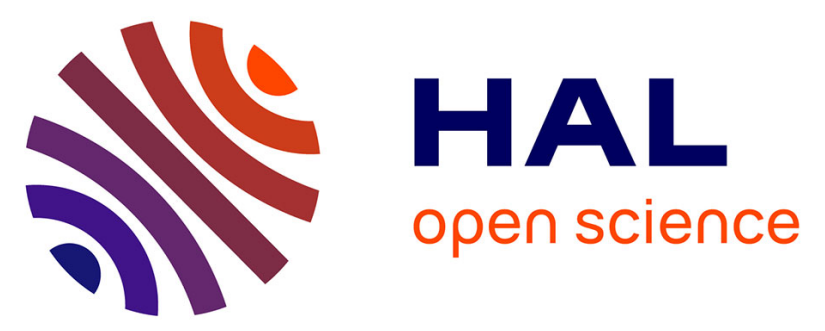

\title{
Real-World Thrombectomy Using the Sofia Catheter
}

Nasreddine Nouri, Marc Ferrigno, Thomas Personnic, Fouzi Bala, Martin Bretzner, Laurent Estrade, Jean-Pierre Pruvo, Hilde Henon, Apolline Kazemi, Nicolas Bricout

\section{- To cite this version:}

Nasreddine Nouri, Marc Ferrigno, Thomas Personnic, Fouzi Bala, Martin Bretzner, et al.. RealWorld Thrombectomy Using the Sofia Catheter. World Neurosurgery, 2019, 122, pp.e1247 - e1251. 10.1016/j.wneu.2018.11.023 . hal-03486483

\section{HAL Id: hal-03486483 https://hal.science/hal-03486483}

Submitted on 20 Dec 2021

HAL is a multi-disciplinary open access archive for the deposit and dissemination of scientific research documents, whether they are published or not. The documents may come from teaching and research institutions in France or abroad, or from public or private research centers.
L'archive ouverte pluridisciplinaire HAL, est destinée au dépôt et à la diffusion de documents scientifiques de niveau recherche, publiés ou non, émanant des établissements d'enseignement et de recherche français ou étrangers, des laboratoires publics ou privés.

\section{다)(1) $(5$}

Distributed under a Creative Commons Attribution - NonCommerciall 4.0 International 


\section{Real-world thrombectomy using the Sofia catheter}

Nouri Nasreddine (M.D.) ${ }^{1}$, Ferrigno Marc (M.D. ${ }^{2,3}$, Personnic Thomas (M.D.) ${ }^{1}$, Bala Fouzi (M.D. $)^{1}$, Bretzner Martin (M.D.) ${ }^{1,3}$, Estrade Laurent (M.D.) $)^{1}$, Pruvo Jean-Pierre (M.D., PhD. $)^{1,3}$, Henon Hilde (M.D., PhD. $)^{2,3}$, Kazemi Apolline (M.D. $)^{1}$, Bricout Nicolas (M.D.) ${ }^{1}$.

${ }^{1}$ Univ. Lille, CHU Lille, Department of Interventional Neuroradiology

${ }^{2}$ Univ. Lille, CHU Lille, Department of Vascular Neurology - stroke unit

${ }^{3}$ INSERM U1171 - Degenerative \& vascular cognitive disorders

Corresponding author: Nicolas Bricout, MD

Interventional Neuroradiology

Hôpital Roger Salengro - CHU de Lille

59000 Lille - France

Phone: (+33) 0320446468

email: bricout.nicolas@gmail.com

Key words: Thrombectomy; Stroke; Catheter 


\title{
Real-world thrombectomy using the Sofia catheter
}

\begin{abstract}
Background We aimed to study the safety and performance of real-world thrombectomy using the Sofia catheter in our comprehensive stroke center.

Methods We conducted a cohort study from a prospective clinical registry of consecutive stroke patients treated by mechanical thrombectomy (MT) between March 2016 and September 2017. Baselines clinical and imaging characteristics, recanalization rates, complications and clinical outcomes were analyzed.

Results: Among the 140 patients included, 54 were treated using aspiration first, 64 were treated using aspiration and stent-retriever straightaway and 22 were treated with Sofia as a rescue device. Successful recanalization (mTICI2b/3) was achieved in $82.1 \%$ patients and good outcome in $34.3 \%$. Symptomatic intracranial hemorrhage occurred in $7.1 \%$ and mortality in $25 \%$.
\end{abstract}

Conclusion: In our single center experience, thrombectomy using the Sofia as an intermediate or aspiration catheter provided high recanalization rates under the everyday conditions. 


\section{Introduction:}

Mechanical thrombectomy (MT) with stent-retriever is the new standard of care for patients with anterior circulation acute ischemic stroke with large vessel occlusion (AIS-LVO) ${ }^{1}$. Recent studies reported high recanalization rates, shorter recanalization time and reduced cost using large bore aspiration catheters as first line recanalization device ${ }^{2,3}$. Other endovascular strategies have been described using a combined approach with a stent-retriever and a distal aspiration catheter ${ }^{4,5}$. The Sofia catheter (MicroVention Inc, Tustin, CA, USA) is an intermediate and aspiration catheter designed for the management of AIS -LVO. We aimed to assess the performance and safety of the SOFIA catheter in the setting of real-world thrombectomy in a single center comprehensive stroke center.

\section{Methods:}

Study design

We conducted a cohort study from the prospective clinical registry of consecutive stroke patients treated by MT in our comprehensive stroke center. The IRB approved the study on December $21^{\text {st }}, 2010\left(n^{\circ} 10.677\right)$. Patients or their relatives gave their informed consent to participate.

\section{Population}

All AIS-LVO patients who underwent MT with the Sofia catheter between March 2016 and September 2017 at a single academic comprehensive stroke center were included for analysis. Eligibility criteria for IV thrombolysis (IVT) and MT were previously published ${ }^{6}$. Upon admission, patients underwent brain MRI with intracranial time-of-flight MR-angiography (TOF-MRA) as first line imaging (or CT / CTA, if presenting a MR contraindication). A follow-up brain MRI was routinely performed 24 to 36 hours after treatment. 


\section{Endovascular Procedure}

MT procedures were usually performed under conscious sedation, using a transfemoral approach. An initial diagnostic cerebral angiogram was performed to assess intracranial clot location (M1 or M2 - middle cerebral artery, intracranial internal carotid artery). A 6-French long introducer sheath (Flexor Shuttle Select, Cook, Bloomington, Indiana, USA) was placed in the internal carotid artery. The Sofia catheter was placed in contact with the clot in a wedge position over a 0.021 ' microcatheter and a 0.014 ' guidewire, the operator could choose between a 5-Fr or 6-Fr Plus Sofia catheter. Choice between Sofia 5F and Sofia Plus 6F catheters was based on operator's preferences, thrombus location and size of the target artery. As a consequence, the Sofia $5 \mathrm{~F}$ catheter was preferred for cases of distal M1 or M2 occlusions, and the Sofia Plus 6F catheter for cases of ICA or proximal M1 occlusions. Clot removal was performed using contact aspiration as the first line treatment (aspiration first group, ADAPT) or in conjunction with a stent-retriever (aspiration \& stent-retriever group, SOLUMBRA) depending on the operator's choice. Aspiration was always performed using a dedicated mechanical pump. In case of tandem occlusion, treatment of the extracranial ICA could involve balloon angioplasty or stenting.

\section{Clinical data collection}

Basic demographic characteristics, including vascular risk factors and vascular history, were prospectively collected. Initial stroke severity was evaluated using the National Institutes of Health Stroke Scale (NIHSS) by stroke neurologists upon admission. Times of symptom onset, groin puncture and recanalization were recorded. The etiology of stroke was determined using the TOAST classification ${ }^{7}$. Symptomatic intracerebral hemorrhage (sICH) was defined according to ECASS-2 criteria ${ }^{8}$. Scores on the modified Rankin scale (mRS) were assessed at 3-months by a stroke neurologist through formal, structured in-person 
interview ${ }^{9}$. For patients who did not undergo the visit with the neurologist, a mRS score was obtained by telephone contact with the patient or a close relative.

Imaging data collection

All images were reviewed by neuroradiologists blinded to clinical data. The extent of ischemia was estimated using DWI-ASPECT scores on baseline imaging. Intracerebral hemorrhage ( $\mathrm{ICH})$ on day-1 imaging was analyzed according to the ECASS criteria adapted to MRI ${ }^{8-10}$. Clot location (M1-MCA, M2-MCA, or intracranial ICA, tandem or extracranial ICA) was assessed on conventional angiography images and reports. Recanalization was rated on the basis of findings on post procedural conventional angiography using the modified Thrombolysis In Cerebral Ischemia (mTICI) scale. Successful recanalization was defined as a grade of $2 \mathrm{~b}$ ( 50 to $99 \%$ reperfusion) or 3 (complete reperfusion) on the mTICI scale ${ }^{11}$. First pass effect was defined as a complete mTICI3 recanalization of the downstream territory after a single pass of a device and no use of rescue therapy. Procedure-related adverse events were recorded.

\section{Outcomes}

The primary end-points were the rate of successful recanalization of the target intracranial artery (mTICI $2 \mathrm{~b}$ or 3 ), complete recanalization (mTICI3), and the incidence of procedure related complications within 24 hours after the procedure. Secondary outcomes were the rate of good functional outcome at 3 months (defined as a mRS score of 0 to 2 or similar to the prestroke $\mathrm{mRS}^{12}$ ), sICH and mortality.

Statistics 
Continuous variables were expressed as mean (standard deviation, SD) or as median (interquartile range, IQR) in cases of non-normal distribution. Normality of distributions was assessed using histograms and the Shapiro-Wilk test. Categorical variables were expressed as frequencies (percentages). Statistical analyses were performed using SPSS version 25 (SPSS Inc., Chicago, IL, USA).

\section{Results:}

Population

Among the 405 anterior-circulation AIS patients treated by MT during the study period, we identified 140 consecutive patients treated with the Sofia catheter. Patients demographics and basic clinical baseline characteristics are reported in Table 1. Overall, the median age was 73 years (IQR, 60 - 83), 52.9\% were female (74/140), 77.9\% (109/140) had a pre-stroke mRS 01, median initial NIHSS was 19 (13 to 24), and 99/140 (70.7\%) patients had an ASPECT score $6-10$ on initial imaging. The intracranial occlusion site was M1-MCA in 78/140 (55.7\%), M2-MCA in 24/140 (17.1\%), intracranial ICA in 20/140 (14.3\%), tandem occlusion in $15 / 140(10.7 \%)$, and extracranial ICA in $3 / 140(2.1 \%)$ patients. IV thrombolysis was administered to $96 / 140(68.6 \%)$ patients prior to MT. Mean time from stroke recognition to groin puncture was 242 min $(\mathrm{SD}, 75)$ and 39 patients $(27.9 \%)$ patients were admitted for a wake-up stroke. The following aspiration catheters were employed: Sofia 5 Fr $(71.4 \%$, $\mathrm{n}=100)$ and Sofia Plus 6 Fr $(28.6 \%, \mathrm{n}=40)$.

\section{Primary outcomes}

Angiographic outcomes are presented in Table 2. Successful recanalization (mTICI $\geq 2 b)$ was achieved in $82.1 \%(115 / 140)$ of patients. Complete recanalization (mTICI 3) was achieved in 69/140 (49.3\%) patients, with a 31.4\% (44/140) first pass effect. The Sofia was successfully 
advanced in contact with the clot in $98.0 \%$ (137/140). Median time of procedure was 32 min (20 to 51) in patients treated with Sofia as first line device.

The ADAPT technique was experienced in 54/140 (38.6\%) patients. Successful recanalization was achieved with this strategy in $42 / 54(77.8 \%)$ after a median procedural time of 29 min (range 9 to 60). However, a stent-retriever was judged necessary in 12/54 (22.2\%) of these patients because of insufficient recanalization after first-line direct aspiration.

The SOLUMBRA technique was used as the first line strategy in 64/140 (45.7\%) patients. It resulted in successful recanalization in 54/64 (84.4\%) patients after a median procedural time of $39 \min$ (22 to 61 ). The first pass effect was $37.0 \%$ with the ADAPT technique and $26.6 \%$ with the SOLUMBRA technique.

The Sofia catheter was used as a rescue device in $22 / 140(15.7 \%)$ patients after failed attempt ( 2 passes or more) of stent-retriever thrombectomy. It resulted in successful recanalization in 19/22 (86.4\%) patients.

Procedure-related complications occurred in 23/140 patients (16.4\%): 11 (7.9\%) groin puncture hematoma, $3(2.1 \%)$ iatrogenic ICA dissection, 2 (1.4\%) intracranial perforation, 1 $(0.1 \%)$ direct carotido-cavernous fistula, and $6(4.3 \%)$ cases of distal emboli in a new territory.

\section{Secondary outcomes}

mRS scores were available for all patients (no missing data). In the overall population, 48/140 (34.3\%) patients achieved good functional outcome at 3 months, and 35/140 (25.0\%) patients died. Symptomatic intracranial hemorrhage $(\mathrm{sICH})$ occurred in 10/136 (7.1\%) patients who underwent day-1 follow-up imaging.

\section{Discussion}


The dramatic increase in the number of patients treated by MT since the publication of MR CLEAN $^{13}$ in 2014 has been associated with the development of new recanalization devices, such as large bore aspiration catheters, which require rigorous evaluation of safety and efficacy. In the ASTER trial ${ }^{2}$, contact aspiration with the Penumbra system has proven non inferiority compared with stentretriever but only a few studies have evaluated MT with the Sofia reperfusion catheter ${ }^{14-16}$. In our single comprehensive stroke center, we aimed to assess safety and efficacy of this novel reperfusion catheter in the setting of real-world clinical practice.

The Sofia catheter reached the clot in all but 3 cases (98\% success), which is in accordance with the literature ${ }^{15}$ and highlights the trackability of the device, allowing an easy access to the occlusion site.

Overall, we showed a $82.1 \%$ rate of successful recanalization. Three recent retrospective case series of stroke patients treated with the Sofia catheter ${ }^{14-16}$ exhibited $96.5 \%(n=85), 86.9 \%$ $(n=115)$, and $90.2 \%(n=41)$ rates of successful recanalisation which appear to be slightly higher than our findings (Table 3). However, these studies did not include stroke patients with tandem occlusion which are considered as more challenging cases with lower successful recanalization rates ${ }^{17}$.

Our study showed $34.3 \%$ patients with good outcome at 3 months and $25.0 \%$ of mortality. These results are similar to outcomes reported in MR CLEAN ${ }^{18}$ (32.6\% mRS 0-2 and 21\% death) despite larger selection criteria. In our center as we included $22 \%$ of patients with prestroke $m R S \geq 2$, and $29 \%$ of patients of low ASPECTS scores (0-5).

We observed 3 cases of iatrogenic ICA dissections that occurred in 2/3 patients with severe vascular tortuosity. The 2 cases of intracranial artery perforations were concomitant with removal of a stent retriever pinched in the aspiration catheter. In one of the two cases, patient died within 24 hours. Thrombus migration in a new vascular territory occurred in $4.3 \%$ of 
cases, which seems lower than previously reported in recent trials (6\% in EXTEND-IA ${ }^{19}$, $15.6 \%$ in MR CLEAN ${ }^{18}$ ). A iatrogenic direct carotid-cavernous fistula occurred in a patient with severe vascular tortuosity treated with a stent-retriever and a 6-Fr Sofia Plus catheter. It remained asymptomatic.

The limitations of this study include the monocentric design and the absence of independent core-lab assessing the clinical and imaging features. Since this is a non-randomized study, we acknowledge selection bias in the comparison between the 2 techniques (ADAPT vs SOLUMBRA) which remains descriptive. However, this is the largest case series of stroke patients treated with the Sofia catheter, with data extracted from a prospective hospital based registry.

\section{Conclusion:}

Thrombectomy with the Sofia as an aspiration or intermediate catheter appeared to be safe and provided high recanalization rates. Our single center experience showed some evidence for safety and efficacy of the Sofia catheter in the treatment of AIS-LVO patients.

\section{Declarations of interest: None}




\section{References}

1. Powers WJ, Derdeyn CP, Biller J, et al. 2015 American Heart Association/American Stroke Association Focused Update of the 2013 Guidelines for the Early Management of Patients With Acute Ischemic Stroke Regarding Endovascular Treatment: A Guideline for Healthcare Professionals From the American Heart Association/American Stroke Association. Stroke. 2015;46(10):3020-3035. doi:10.1161/STR.0000000000000074

2. Lapergue B, Labreuche J, Blanc R, et al. First-line use of contact aspiration for thrombectomy versus a stent retriever for recanalization in acute cerebral infarction: The randomized ASTER study protocol. Int J Stroke. 2018;13(1):87-95. doi:10.1177/1747493017711948

3. Turk AS, Frei D, Fiorella D, et al. ADAPT FAST study: a direct aspiration first pass technique for acute stroke thrombectomy. J Neurointerventional Surg. 2014;6(4):260264. doi:10.1136/neurintsurg-2014-011125

4. Massari F, Henninger N, Lozano JD, Patel A, Kuhn AL, Howk M, et al. ARTS (Aspiration-Retriever Technique for Stroke): Initial clinical experience. Interv Neuroradiol. juin 2016;22(3):325]32.

5. Maus V, Behme D, Kabbasch C, Borggrefe J, Tsogkas I, Nikoubashman O, et al. Maximizing First-Pass Complete Reperfusion with SAVE. Clin Neuroradiol. 13 févr 2017;1国12.

6. Ferrigno M, Bricout N, Leys D, Estrade L, Cordonnier C, Personnic T, et al. Intravenous Recombinant Tissue-Type Plasminogen Activator: Influence on Outcome in Anterior Circulation Ischemic Stroke Treated by Mechanical Thrombectomy.Stroke. juin 2018;49(6):1377?85.

7. Adams HP, Bendixen BH, Kappelle LJ, Biller J, Love BB, Gordon DL, et al. Classification of subtype of acute ischemic stroke. Definitions for use in a multicenter clinical trial. TOAST. Trial of Org 10172 in Acute Stroke Treatment. Stroke. 1 janv 1993;24(1):35回41.

8. Hacke W, Kaste M, Fieschi C, von Kummer R, Davalos A, Meier D, et al. Randomised double-blind placebo-controlled trial of thrombolytic therapy with intravenous alteplase in acute ischaemic stroke (ECASS II). Second European-Australasian Acute Stroke Study Investigators. Lancet Lond Engl. 17 oct 1998;352(9136):1245ㅁ⒈

9. van Swieten JC, Koudstaal PJ, Visser MC, Schouten HJ, van Gijn J. Interobserver agreement for the assessment of handicap in stroke patients. Stroke. 1 mai 1988;19(5):604国7.

10. Neeb L, Villringer K, Galinovic I, Grosse-Dresselhaus F, Ganeshan R, Gierhake D, et al. Adapting the Computed Tomography Criteria of Hemorrhagic Transformation to Stroke Magnetic Resonance Imaging. Cerebrovasc Dis Extra. 2013;3(1):103?10. 
11. Zaidat OO, Yoo AJ, Khatri P, Tomsick TA, von Kummer R, Saver JL, et al. Recommendations on angiographic revascularization grading standards for acute ischemic stroke: a consensus statement. Stroke. sept 2013;44(9):2650?63.

12. IST-3 collaborative group, Sandercock P, Wardlaw JM, et al. The benefits and harms of intravenous thrombolysis with recombinant tissue plasminogen activator within $6 \mathrm{~h}$ of acute ischaemic stroke (the third international stroke trial [IST-3]): a randomised controlled trial. Lancet Lond Engl. 2012;379(9834):2352-2363. doi:10.1016/S01406736(12)60768-5

13. Olvert A. Berkhemer, M.D., Puck S.S. Fransen, M.D., Debbie Beumer, M.D., Lucie A. van den Berg, M.D., Hester F. Lingsma, Ph.D., Albert J. Yoo, M.D., Wouter J. Schonewille, M.D., Jan Albert Vos, M.D., Ph.D., Paul J. Nederkoorn, M.D., Ph.D., Marieke J.H. Wermer, M.D., Ph.D., Marianne A.A. van Walderveen, M.D., Ph.D., Julie Staals, M.D., Ph.D., et al., for the MR CLEAN Investigators*. A Randomized Trial of Intraarterial Treatment for Acute Ischemic Stroke.

14. Möhlenbruch MA, Kabbasch C, Kowoll A, et al. Multicenter experience with the new SOFIA Plus catheter as a primary local aspiration catheter for acute stroke thrombectomy. J NeuroInterventional Surg. 2017;9(12):1223-1227. doi:10.1136/neurintsurg-2016-012812

15. Shallwani H, Shakir HJ, Rangel-Castilla L, et al. Safety and Efficacy of the Sofia (6F) PLUS Distal Access Reperfusion Catheter in the Endovascular Treatment of Acute Ischemic Stroke. Neurosurgery. 2018;82(3):312-321. doi:10.1093/neuros/nyx 169

16. Stampfl S, Kabbasch C, Müller M, et al. Initial experience with a new distal intermediate and aspiration catheter in the treatment of acute ischemic stroke: clinical safety and efficacy. J Neurointerventional Surg. 2016;8(7):714-718. doi:10.1136/neurintsurg-2015011801

17. Fahed R, Redjem H, Blanc R, et al. Endovascular Management of Acute Ischemic Strokes with Tandem Occlusions. Cerebrovasc Dis. 2016;41(5-6):298-305. doi: $10.1159 / 000444068$

18. Berkhemer OA, Fransen PSS, Beumer D, et al. A Randomized Trial of Intraarterial Treatment for Acute Ischemic Stroke. N Engl J Med. December 2014. doi:10.1056/NEJMoa1411587

19. Campbell BCV, Mitchell PJ, Kleinig TJ, et al. Endovascular Therapy for Ischemic Stroke with Perfusion-Imaging Selection. N Engl J Med. February 2015:150211090353006. doi:10.1056/NEJMoa1414792 
$\underline{\text { Table 1: Patients demographics and baseline characteristics }}$

\section{Overall}

Characteristics

$(n=140)$

\section{Demographics and medical history}

Age, yr, median (IQR)

73 (60 to 83$)$

Pre stroke mRS 0-1

$109(77.9 \%)$

Female

$74(52.9 \%)$

Hypertension

$92(65.7 \%)$

Diabetes

$39(27.8 \%)$

Hypercholesterolemia

$62(44.2 \%)$

Former or current smoking

$56(40.0 \%)$

\section{Current stroke event}

Admission NIHSS, median (IQR)

19 (13 to 24$)$

Wakeup stroke

$39(27.9 \%)$

ASPECTS 6 - 10

$99(70.7 \%)$

Intracranial Occlusion site

- M1-MCA

$78(55.7 \%)$

- M2-MCA

$24(17.1 \%)$

- Intracranial ICA

$20(14.3 \%)$

- $\quad$ Tandem occlusion

$15(10.7 \%)$

- $\quad$ Extracranial ICA

$3(2.1 \%)$

Stroke etiology

- $\quad$ TOAST 1 (atherosclerosis)

$10(7.1 \%)$

- $\quad$ TOAST 2 (embolism)

$70(50.0 \%)$ 
- $\quad$ TOAST 3 (other known cause)

$11(7.8 \%)$

- $\quad$ TOAST 4 (unknown)

$49(35.0 \%)$

\section{Revascularization procedures}

IV thrombolysis prior MT

$96(68.6 \%)$

Conscious sedation

$140(100 \%)$

Onset to puncture, min, mean (SD)

$242(75)$

Values are number (\%), mean (SD) or median (IQR).

Abbreviations: ICA, internal carotid artery ; IVT, intravenous thrombolysis ; MT, mechanical thrombectomy ; MCA, middle cerebral artery; IQR, interquartile range 
$\underline{\text { Table 2: Procedural characteristics and angiographic outcomes }}$

\section{Overall ADAPT SOLUMBRA Rescue}

Population

140

$54(38.6 \%)$

$64(45.7 \%)$

$22(15.7 \%)$

\section{Occlusion sites}

$M 1-M C A$

$78(55.7 \%) \quad 28(51.9 \%) \quad 36(56.3 \%) \quad 14(63.6 \%)$

$M 2-M C A$

$24(17.1 \%) \quad 15(27.8 \%)$

$8(12.5 \%) \quad 1(4.5 \%)$

Intracranial ICA

$20(14.3 \%) \quad 7(13.0 \%) \quad 9(14.1 \%) \quad 4(18.2 \%)$

Tandem

$15(10.7 \%) \quad 3(5.6 \%)$

$10(15.6 \%) \quad 2(9.1 \%)$

Extracranial ICA

$3(2.1 \%) \quad 1(1.9 \%)$

$1(1.6 \%)$

$1(4.5 \%)$

\section{Outcomes}

\begin{tabular}{|c|c|c|c|c|}
\hline$m$ TICI 3 & $69(49.3 \%)$ & $25(46.3 \%)$ & $30(46.9 \%)$ & $14(63.6 \%)$ \\
\hline$m T I C I 2 b-3$ & $115(82.1 \%)$ & $42(77.8 \%)$ & $54(84.4 \%)$ & $19(86.4 \%)$ \\
\hline $\begin{array}{l}\text { Time of procedure, min } \\
\text { median (IQR) }\end{array}$ & $32(20-51)$ & $29(9-60)$ & $39(22-61)$ & NA \\
\hline First pass effect & $44(31.4 \%)$ & $20(37.0 \%)$ & $17(26.6 \%)$ & NA \\
\hline
\end{tabular}

Values are number $(\%)$ or median (IQR).

Abbreviations: ICA, internal carotid artery ; MCA, middle cerebral artery; IQR, interquartile range; mTICI, modified thrombolysis in cerebral infarction. 
Table 3: Safety profiles of the Sofia catheter in stroke treatment

\begin{tabular}{llccc}
\hline \multirow{2}{*}{ Study } & Anterior & Successful & \\
& & TICI 2b/3 & Complications \\
& circulation & & placement & \\
& & & & \\
\hline
\end{tabular}

This study
$n=140$
Möhlenbruch et al.

$n=85 \quad$ Sofia 6F Plus

Sofia $5 \mathrm{~F}$

Sofia 6F Plus

$100 \% \quad 82.1 \% \quad 91.8 \%$

Embolus (4.3\%)

$n=85$

$94.1 \%$

96.5

Embolus (4.7\%)

$\operatorname{sICH}(7.1 \%)$

Dissection $(2.1 \%)$

Perforation (1.4\%)

Stampfl et al.

$\begin{array}{llllll}n=115 & \text { Sofia } 5 \mathrm{~F} & 84.3 \% & 86.9 \% & 96 \% & \text { Embolus (2.6\%) }\end{array}$

Shallwani et al.

Sofia 6F Plus

$97.5 \%$

$90.2 \%$

$92.7 \%$

Embolus (4.8\%)

$n=41$

Dissection $(2.4 \%)$

Perforation $(7.3 \%)$

sICH: Symptomatic intracranial Hemorrhage, Embolus : Thrombus migration to a new vascular territory, Dissection : cervical artery dissection, Perforation : intracranial artery perforation. 